\title{
LOSARTAN POTASSIUM DISSOLUTION TEST FOR DRUG RELEASE EVALUATION IN PHARMACEUTICAL CAPSULES USING HPLC AND UV SPECTROPHOTOMETRY
}

\author{
Rudy Bonfilio*, Taciane Ferreira Mendonça, Gislaine Ribeiro Pereira e Magali Benjamim de Araújo \\ Departamento de Farmácia, Universidade Federal de Alfenas, Rua Gabriel Monteiro da Silva, 700, 37130-000 Alfenas - MG, Brasil \\ César Ricardo Teixeira Tarley \\ Departamento de Ciências Exatas, Universidade Federal de Alfenas, Rua Gabriel Monteiro da Silva, 700, 37130-000 Alfenas - MG, Brasil
}

Recebido em 15/4/09; aceito em 27/7/09; publicado na web em 11/1/10

\begin{abstract}
This work describes the development and validation of a dissolution test for $50 \mathrm{mg}$ losartan potassium capsules using HPLC and UV spectrophotometry. A $2^{4}$ full factorial design was carried out to optimize dissolution conditions and potassium phosphate buffer, $\mathrm{pH} 6.8$ as dissolution medium, basket as apparatus at the stirring speed of $50 \mathrm{rpm}$ and time of $30 \mathrm{~min}$ were considered adequate. Both dissolution procedure and analytical methods were validated and a statistical analysis showed that there are no significant differences between HPLC and spectrophotometry. Since there is no official monograph, this dissolution test could be applied for quality control routine.
\end{abstract}

Keywords: losartan potassium; full factorial design; dissolution.

\section{INTRODUCTION}

The quality assurance of pharmaceutical products is a wide-ranging concept covering all matters that individually or collectively influence the quality of a product. In this sense, the importance of in vitro dissolution tests for immediate release solid oral dosage forms, such as tablets and capsules must be highlighted, since they are essential to evaluate the lot-to-lot quality of a drug product, to guide development of new formulations and to ensure continuing product quality and performance after certain changes, such as changes in the formulation, the manufacturing process, the site of manufacture, and the scale-up of the manufacturing process. ${ }^{1}$ Although immediate release solid dosage forms are routinely subjected to tests such as content uniformity, weight, hardness, friability and disintegration, the test that is most often associated with the assessment of in vivo performance is the dissolution test. ${ }^{2}$

Therefore, undoubtedly, there is a real need to develop dissolution tests for pharmaceutical products to assure the quality and to attend the regulatory demands.

Losartan potassium (Figure 1), 2-butyl-4-chloro-1-[ $p$ - $(o-1 H$-tetrazol-5-ylphenyl)benzyl] imidazole-5-methanol monopotassium salt, ${ }^{3}$ was the first of a new class of orally active, non-peptide angiotensin II receptor (type AT1) antagonist for the treatment of hypertension. Losartan has been demonstrated to be superior to previous peptide receptor antagonists and angiotensin converting enzyme (ACE) inhibitors because of its enhanced specificity, selectivity and tolerability, ${ }^{4,5}$ Losartan potassium has a molecular weight of 461; a pKa value of 4.9; an aqueous solubility of $3.3 \mathrm{mg} \mathrm{mL}^{-1}$ at $\mathrm{pH} 7.8^{6}$ and exhibits highly variable and low oral bioavaiability (approximately 33\%). ${ }^{7,8}$ Losartan is, therefore, considered class 3 in the biopharmaceutics classification system, because it has high solubility and low permeability.

Several analytical methods have been applied to the analysis of losartan potassium in biological fluids using high performance liquid chromatography technique (HPLC) ${ }^{9-13}$ For applications in pharmaceutical products there are methods that make use of HPLC, ${ }^{14-22}$ high performance thin layer chromatography (HPTLC), ${ }^{23,24}$ capillary electrophoresis (CE), capillary electrochromatography $(\mathrm{CEC})^{25}$ and spectrophotometry. ${ }^{26-28}$ Recently, the literature presents the employment of the HPLC for bioequivalence studies of tablets containing losartan potassium..$^{29,30}$

\footnotetext{
*e-mail: rudybonfilio@yahoo.com.br
}

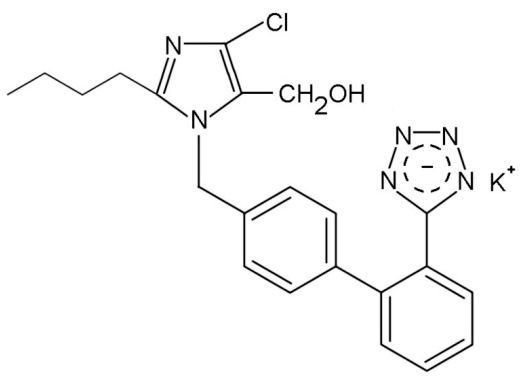

Figure 1. Chemical structure of losartan potassium

At the best of our knowledge, there is no dissolution tests described in literature for losartan potassium in pharmaceutical capsules and not any pharmacopoeia described an official method. The aim of this work is to establish conditions for a dissolution test for losartan potassium capsules using a multivariate approach, to validate the test and quantitation methods, to evaluate three different commercial products and to compare HPLC and spectrophotometric methods.

The multivariate experimental design provides a reduction in the number of required experiments, is faster to implement and more cost-effective than traditional univariate approaches. Therefore, a full factorial design was found to be suitable for the purpose of this work.

\section{EXPERIMENTAL}

\section{Chemical and reagents}

All reagents were of analytical grade. Potassium dihydrogenphosphate $\left(\mathrm{KH}_{2} \mathrm{PO}_{4}\right)$, phosphoric acid, sodium hydroxide, HPLC grade acetonitrile and hydrochloride acid were purchased from $\mathrm{Vetec}^{\circledR}$ (Rio de Janeiro, Brazil). 98.90\% purity losartan potassium salt was supplied by IPCA laboratories limited ${ }^{\circledR}$ (Athal, Indian). $50 \mathrm{mg}$ losartan potassium salt in capsules were supplied by three local drugstores from three different Brazilian manufactures, codified as A, B and C. The placebo mixture used in accuracy and selectivity studies containing pharmaceutical grade excipients (magnesium stearate, aerosil, sodium dodecyl sulfate, talc, starch and microcel MC-102 1) were obtained from the same local drugstores (A, B and C). 


\section{Instrumentation}

Dissolution tests were performed in an Electrolab ${ }^{\circledR}$ TDT-08 L multi bath $(\mathrm{n}=8)$ dissolution test system (Mumbai, India), in accordance with The United States Pharmacopoeia (USP) general method. ${ }^{3}$

UV visible spectrophotometer used was a Shimadzu ${ }^{\circledR}$ model 1601 (Kyoto, Japan), connected to a computer loaded with Shimadzu UVPC version 3.9 software.

The HPLC equipment used was a Shimadzu ${ }^{\circledR}$ series LC-10A (Kyoto, Japan), consisting of a LC AVP pump, a CLASS-VP 5.02 integration system, a DGU-14 A degasser, a 7725i manual injector with a $20 \mu \mathrm{L}$ loop, (Rheodyne ${ }^{\circledR}$, California, United States), a SPD-10AVP integrated UV detector, a FCV-10ALVP valve, a CTO10AVP column oven and a SCL-10 AVP controller. A Nucleosil RP8 analytical column, $5 \mu \mathrm{m}$ particle size, $125 \times 4.6 \mathrm{~mm}$ i.d. (Macherey $\mathrm{Nagel}^{\circledR}$, Düren, Germany) with a guard column $(20 \times 4.6 \mathrm{~mm}$ i.d. $)$ was used in this study.

The following equipments were also used: digital pHmeter PA 200 (Marconi ${ }^{\circledR}$ S.A., Piracicaba, Brazil); ultrasonic Bath model USC2800A (Unique ${ }^{\circledR}$, São Paulo, Brazil); analytical balance model 410 (Kern ${ }^{\circledR}$, Kern, Germany); reverse osmosis water purifier OS 10 LTH (Gehaka ${ }^{\circledR}$, São Paulo, Brazil); vacuum filtration system (Millipore ${ }^{\circledR}$, Bedford, United States) and disintegrator model 299-6 (Nova Ética ${ }^{\circledR}$, São Paulo, Brazil).

\section{Solutions}

All dissolution media used in this study (water and phosphate buffer, $\mathrm{pH}$ 6.8) were degassed at $41{ }^{\circ} \mathrm{C}$ in ultrasonic bath for $30 \mathrm{~min}$ prior to use.

A buffer potassium phosphate at $\mathrm{pH} 6.8$ was prepared by adding $13.6 \mathrm{~g}$ of potassium dihydrogenphosphate and $224 \mathrm{~mL}$ of $0.2 \mathrm{~mol}$ $\mathrm{L}^{-1}$ sodium hydroxide in $2.0 \mathrm{~L}$ of water. The $\mathrm{pH}$ value was checked with the $\mathrm{pHmeter}$.

The stock solutions of losartan potassium were prepared in a 50 $\mathrm{mL}$ volumetric flask by dissolving an accurately weighed amount (27.8 $\mathrm{mg}$ ) of losartan potassium standard $(98.90 \%$ purity) in potassium phosphate buffer or purified water depending on the dissolution medium used. This solution was filtered in a quantitative Vetec filter paper. Working standard solutions were prepared immediately before use, by appropriate dilutions of the corresponding stock solutions of losartan potassium with potassium phosphate buffer or purified water.

Placebo solutions were prepared by dissolving an amount accurately weighed of placebo mixture (containing the same amount of the products $\mathrm{A}, \mathrm{B}$ and $\mathrm{C}$ ) in potassium phosphate buffer.

Sample solutions were prepared by putting one capsule in each vessel containing the dissolution medium $(900 \mathrm{~mL})$ at the temperature of $37 \pm 0.5^{\circ} \mathrm{C}$. Samples were collected at the end of the specified time and filtered in a quantitative Vetec filter paper. For the HPLC analysis, samples were directly injected into the HPLC system. In the spectrophotometric analysis, $2.5 \mathrm{~mL}$ of the samples were transferred into a $25 \mathrm{~mL}$ volumetric flask, later completed with dissolution medium.

To avoid interference from the capsule shell in the spectrophotometric quantitation, blank solutions were prepared by dissolving capsule shells of each brand (A, B and C) into the same medium and performed the dissolution test in the same manner as the samples. Any absorbance obtained from the blank solutions was subtracted from the absorbance of the sample solutions.

\section{Spectrophotometric measurements}

Spectra of losartan potassium standard were built in the range from 400 to $200 \mathrm{~nm}$ using $1 \mathrm{~cm}$ quartz cuvettes in the fast scan speed,
$2.0 \mathrm{~nm}$ data interval and $2 \mathrm{~nm}$ bandwidth. The percentage of drug release (DR\%) was assayed at the wavelength of $205 \mathrm{~nm}$.

\section{HPLC analytical procedure}

The volume of injection was twenty microliters. All solutions were filtered through a $0.45 \mu \mathrm{m}$ millex-LCR filter before the injection in the column. The flow rate was set at $1.00 \mathrm{~mL} \mathrm{~min}^{-1}$ with a mobile phase of potassium phosphate buffer ( $\left.\mathrm{pH} 6.2 ; 58 \mathrm{mmol} \mathrm{L}^{-1}\right)$ - acetonitrile $(65: 35, \mathrm{v} / \mathrm{v})$. The mobile phase was filtered under vacuum through $0.45 \mu \mathrm{m}$ modified hydrophillic PTFE membrane and degassed ultrasonically for $30 \mathrm{~min}$ prior to use. The column temperature was maintained at $35^{\circ} \mathrm{C}$. Peak areas were taken as analytical signal, with detection at $254 \mathrm{~nm}$.

\section{Sink conditions}

In order to establish sink conditions, the solubility of the drug was tested using $100 \mathrm{mg}$ of losartan potassium in $300 \mathrm{~mL}$ of 0.1 mol L-1 $\mathrm{HCl}, 0.01 \mathrm{~mol} \mathrm{~L}^{-1} \mathrm{HCl}$, phosphate buffer, $\mathrm{pH} 6.8$ and water.

\section{Dissolution experiments based on factorial design of each factor}

In order to evaluate the significance of each factor in the dissolution conditions, a $2^{4}$ full factorial design was performed in duplicate in a total of 16 experiments for each sample (A, B and C). The following parameters were investigated: dissolution medium (water and potassium phosphate buffer, $\mathrm{pH}$ 6.8); apparatus (basket and paddle); stirring time (30 and $60 \mathrm{~min}$ ) and stirring speed (50 and $100 \mathrm{rpm}$ ). These factors and their levels are listed in Table 1.

Table 1. Factors and levels employed in the building of the $2^{4}$ full factorial design

\begin{tabular}{lcc}
\hline Factors & \multicolumn{2}{c}{ Levels } \\
\hline F1-Dissolution medium & Water & $(+)$ Pow High \\
F2-Apparatus & Basket & Paddle \\
F3-Time & $30 \mathrm{~min}$ & $60 \mathrm{~min}$ \\
F4-Stirring speed & $50 \mathrm{rpm}$ & $100 \mathrm{rpm}$ \\
\hline
\end{tabular}

The main effects of each studied factor and the variance of each experiment were calculated according to literature ${ }^{31}$ and the standard variance $\left(\mathrm{S}_{\mathrm{p}}{ }^{2}\right)$ of the factors was calculated via Equation 1:

$s_{p}^{2}=\frac{\left(n_{A}-1\right) s_{A}^{2}+\left(n_{B}-1\right) s_{B}^{2}}{\left(n_{A}-1\right)+\left(n_{B}-1\right)}$

where $n$ is the number of times that the assay was repeated and $s^{2}$ is the variance obtained in each assay. After that, the variance of the effects was obtained from Equation 2:

$$
V(\text { estimate })=V[\bar{R}(+)]+V[\bar{R}(-)]=\frac{s_{p}{ }^{2}}{n}+\frac{s_{p}{ }^{2}}{n}
$$

where $n$ is the number of assays with low (8) and high (8) levels. The error of the effects was obtained by extracting the root of the variance. By multiplying the error by the critical $t_{n-1}$ with 16 degree of freedom $(2.120)^{31}$ for a confidence interval of $95 \%$, it was obtained the estimated error for each product. 


\section{Method validation}

\section{Selectivity}

For determination of selectivity, the placebo samples and empty capsules of each product (A, B and C, respectively) were transferred to separate vessels $(\mathrm{n}=6)$ containing $900 \mathrm{~mL}$ of dissolution medium at $37 \pm 0.5^{\circ} \mathrm{C}$ and stirred for $60 \mathrm{~min}$ at $150 \mathrm{rpm}$ using basket as apparatus. Aliquots were collected and the interference of empty capsules and placebo mixture of each formulation was evaluated by HPLC and spectrophotometry. This procedure was made according to literature. ${ }^{32}$

\section{Linearity}

Linearity was evaluated according to the ICH guidelines, ${ }^{33}$ by the analysis of standard solutions in the final concentrations of 30.0, 40.0, 50.0, 60.0 and $70.0 \mathrm{mg} \mathrm{L}^{-1}$ of losartan potassium in phosphate buffer $\mathrm{pH}=6.8$ using HPLC detection. The calibration curve using spectrophotometry was obtained in the final concentrations of 3.0, 4.0, 5.0, 6.0 and 7.0 $\mathrm{mg} \mathrm{L}^{-1}$ of losartan potassium in phosphate buffer $\mathrm{pH}=6.8$. The calculation of regression line was employed by the method of least squares.

\section{Repeatability (intra-assay) and intermediate precision (inter-} assay) of the analytical methods

The repeatability of analytical methods was validated by analysis of six standard solutions of losartan potassium dissolved in phosphate buffer $\mathrm{pH}=6.8$ at the concentrations of 55.6 and $5.56 \mathrm{mg} \mathrm{L}^{-1}$ using HPLC and spectrophotometry, respectively (100\% levels). The intermediate precisions of methods were determined similarly but a second analyst repeated the procedure in a different day. The R.S.D values for determinations were calculated. ${ }^{33}$

Repeatability (intra-assay) and intermediate precision (interassay) of the dissolution procedure

The repeatability of dissolution procedure was accomplished according to literature, ${ }^{34}$ by submitting six samples of each product (A, B and $\mathrm{C}$ ) to the optimized dissolution test. Aliquots were collected and evaluated by HPLC and spectrophotometry at $205 \mathrm{~nm}$. The intermediate precisions were determined similarly but a second analyst repeated the procedure in a different day. The R.S.D values for determinations were calculated.

\section{Accuracy of the analytical methods}

Accuracy of the analytical methods was carried out by the addition of losartan potassium stock standard solution to placebo mixtures A, B and $\mathrm{C}$ in $25 \mathrm{~mL}$ volumetric flasks, to obtain three final concentration levels, corresponding to 80,100 and $120 \%$ of target concentration of each quantitation method (HPLC and spectrophotometry). Each solution was prepared in triplicate. The percent recoveries were calculated. ${ }^{33}$

\section{Accuracy of the dissolution procedure}

Accuracy of dissolution tests was determined according to literature, ${ }^{34}$ by the addition of 40,50 and $60 \mathrm{mg}$ of losartan potassium to placebo mixtures $\mathrm{A}, \mathrm{B}$ and $\mathrm{C}$ in vessels containing $900 \mathrm{~mL}$ of dissolution medium (phosphate buffer, $\mathrm{pH}=6.8$ ). The samples were submitted to optimized dissolution test. Aliquots were collected and analyzed by HPLC and spectrophotometry at $205 \mathrm{~nm}$. These studies were performed in triplicate. The percent recoveries were calculated.

\section{Detection limit and quantitation limit}

Detection limit (DL) and quantitation limit (QL) of the HPLC method were determined based on the $\mathrm{S} / \mathrm{N}$ criteria, according to $\mathrm{ICH}$ recommendations..$^{33}$ The signal-to-noise ratio was 3:1 for DL and 10:1 for QL. The noise was measured from chromatograms of blank (phosphate buffer, $\mathrm{pH}=6.8$ ).
The detection (DL) and quantitation (QL) limits of the UV spectrophotometric method were obtained from the Equations 3 and 4:

$\mathrm{DL}=3(\mathrm{~S} . \mathrm{D} / a)$

$\mathrm{QL}=10(\mathrm{~S} . \mathrm{D} / a)$

where S.D. is standard deviation of the 20 spectrophotometric readings of blank (phosphate buffer, $\mathrm{pH}=6.8$ ). and $a$ is slope of calibration curves obtained in the linearity study.

\section{Disintegration}

All capsules formulations were subject to a disintegration test according general chapters to United States Pharmacopoeia. ${ }^{3}$ All tests were conducted using water at $37 \pm{ }^{\circ} \mathrm{C}$. Six capsules per formulation were tested.

\section{Dissolution profiles}

The dissolution profiles were obtained after determining the best dissolution condition tests as well as the validation. Potassium phosphate buffer, pH 6.8 was used as dissolution medium, basket as apparatus at the stirring speed of $50 \mathrm{rpm}$ and vessel volume of 900 $\mathrm{mL}$. Aliquots of $5 \mathrm{~mL}$ were withdrawn from each vessel and the same volume of the dissolution medium was replaced to maintain a constant total volume. The times selected were $2 ; 5 ; 10 ; 20 ; 30$ and $60 \mathrm{~min}$. Six samples were assayed for each product using both HPLC and spectrophotometry.

\section{Comparison of methods}

A factorial design $6 \times 3 \times 2$ (six time points, three products and two methods) with six repetitions was used together with a statistical method based on the analysis of variance (ANOVA) in order to compare the analytical methods (UV spectrophotometry x HPLC) at 0.05 significance level.

\section{RESULTS AND DISCUSSION}

\section{Spectrophotometric conditions}

The ultraviolet spectrum for losartan potassium, in water and potassium phosphate buffer showed maximum drug absorption wavelength at $205 \mathrm{~nm}$. Therefore, this wavelength was used for the losartan potassium spectrophotometric quantitation throughout the study.

\section{Optimization of HPLC conditions}

In the HPLC analysis, the chromatographic conditions were based on the previous work, ${ }^{35}$ in which a HPLC method for the quantitation of losartan potassium in pharmaceutical capsules was developed and validated. In order to confirm if the chromatographic parameters are in accordance with literature, a system suitability test was carried out by injecting six replicates of a work standard solution of losartan potassium containing $55.5 \mathrm{mg} \mathrm{L}^{-1}$. The retention time was 2.92 min; theoretical plates higher than 4100; capacity factor of 2.19 and asymmetry of 1.30 . The relative standard deviation of peak area was $0.96 \%$. Thus, all parameters are in agreement to the United States Pharmacopeia recommendations. ${ }^{3}$

\section{Optimization strategy of dissolution experiments}

The experiments were performed in duplicate for the products A, $\mathrm{B}$ and $\mathrm{C}$ using a $2^{4}$ full factorial design in a total of 16 experiments 
Table 2. Design matrix and experimental results obtained from the $2^{4}$ full factorial design

\begin{tabular}{|c|c|c|c|c|c|c|c|c|c|c|}
\hline \multirow{2}{*}{ Tests } & \multirow{2}{*}{$\mathrm{F} 1$} & \multirow{2}{*}{$\mathrm{F} 2$} & \multirow{2}{*}{ F3 } & \multirow{2}{*}{ F4 } & \multicolumn{3}{|c|}{ HPLC } & \multicolumn{3}{|c|}{ Spectrophotometry } \\
\hline & & & & & Product A (\%) & Product B (\%) & Product C (\%) & Product A (\%) & Product B (\%) & Product C (\%) \\
\hline 1 & - & - & - & - & $89.7 / 95.6$ & $90.30 / 87.77$ & $106.4 / 104.0$ & $87.8 / 98.8$ & $90.2 / 92.4$ & $104.0 / 95.1$ \\
\hline 2 & + & - & - & - & $95.3 / 95.4$ & $96.2 / 96.0$ & $108.4 / 106.2$ & $93.3 / 95.2$ & $97.0 / 93.3$ & $102.2 / 98.1$ \\
\hline 3 & - & + & - & - & $94.8 / 103.2$ & $97.5 / 94.0$ & 98.9/103.8 & $97.4 / 107.7$ & $99.6 / 93.0$ & 100.9/101.9 \\
\hline 4 & + & + & - & - & $92.7 / 96.1$ & $93.6 / 90.6$ & $101.4 / 104.3$ & $90.2 / 96.6$ & $98.3 / 93.6$ & $96.2 / 99.2$ \\
\hline 5 & - & - & + & - & $96.8 / 99.3$ & $88.7 / 93.0$ & $94.4 / 102.3$ & $93.5 / 99.3$ & $83.9 / 90.3$ & $93.2 / 91.9$ \\
\hline 6 & + & - & + & - & $91.6 / 99.9$ & $97.0 / 95.6$ & $96.2 / 106.3$ & $89.4 / 97.9$ & $87.4 / 91.5$ & $89.1 / 96.7$ \\
\hline 7 & - & + & + & - & $96.7 / 97.3$ & $94.2 / 92.4$ & $98.3 / 102.8$ & $91.3 / 84.6$ & $89.9 / 88.0$ & $92.5 / 92.7$ \\
\hline 8 & + & + & + & - & $95.3 / 89.6$ & $90.5 / 94.0$ & $101.7 / 113.4$ & $91.4 / 91.3$ & $90.20 / 90.57$ & $92.4 / 98.7$ \\
\hline 9 & - & - & - & + & $93.5 / 94.5$ & $92.0 / 89.7$ & $113.5 / 100.5$ & $95.5 / 94.9$ & $91.1 / 86.9$ & $107.3 / 97.6$ \\
\hline 10 & + & - & - & + & $94.1 / 95.1$ & $97.8 / 97.1$ & 103.0/101.9 & $98.0 / 97.7$ & $93.8 / 89.2$ & $94.7 / 91.4$ \\
\hline 11 & - & + & - & + & $97.4 / 104.4$ & $99.1 / 90.5$ & $100.3 / 99.6$ & $95.4 / 106.7$ & $98.5 / 89.4$ & $100.3 / 99.6$ \\
\hline 12 & + & + & - & + & $95.6 / 99.1$ & $92.9 / 90.5$ & $91.2 / 105.0$ & $93.5 / 92.3$ & $92.1 / 88.6$ & $93.3 / 95.7$ \\
\hline 13 & - & - & + & + & $101.9 / 96.8$ & $86.1 / 92.4$ & $93.4 / 100.9$ & $100.1 / 96.4$ & $81.1 / 87.5$ & $97.1 / 97.9$ \\
\hline 14 & + & - & + & + & $89.3 / 93.2$ & $101.3 / 100.3$ & $110.2 / 106.3$ & $86.8 / 92.1$ & $97.9 / 96.4$ & $93.2 / 100.3$ \\
\hline 15 & - & + & + & + & $97.0 / 94.1$ & $95.8 / 93.7$ & $97.2 / 115.6$ & $96.2 / 94.2$ & $92.9 / 91.8$ & $90.5 / 98.3$ \\
\hline 16 & + & + & + & + & $92.1 / 95.2$ & $92.0 / 96.0$ & $104.1 / 103.0$ & $94.1 / 90.9$ & $88.90 / 90.38$ & $94.1 / 98.5$ \\
\hline
\end{tabular}

Table 3. Effects of the factors and estimated errors on the drug release percent (DR\%) for products A, B and C

\begin{tabular}{|c|c|c|c|c|c|c|c|}
\hline \multirow{2}{*}{ Method } & \multirow{2}{*}{ Factor } & \multicolumn{2}{|c|}{ Product A } & \multicolumn{2}{|c|}{ Product B } & \multicolumn{2}{|c|}{ Product C } \\
\hline & & Effects & Estimated error & Effects & Estimated error & Effects & Estimated error \\
\hline \multirow[t]{4}{*}{ HPLC } & $\mathrm{F} 1$ & 1.11 & \multirow{4}{*}{2.48} & -0.24 & \multirow{4}{*}{1.93} & -0.82 & \multirow{4}{*}{2.90} \\
\hline & $\mathrm{F} 2$ & -0.71 & & 0.47 & & -0.15 & \\
\hline & F3 & -0.30 & & 1.02 & & -0.19 & \\
\hline & $\mathrm{F} 4$ & $-2.78^{*}$ & & $2.77 *$ & & 1.90 & \\
\hline \multirow[t]{4}{*}{ Spectrophotometry } & $\mathrm{F} 1$ & -0.18 & \multirow{4}{*}{3.27} & 1.63 & \multirow{4}{*}{2.39} & -0.32 & \multirow{4}{*}{2.80} \\
\hline & $\mathrm{F} 2$ & -3.24 & & $-3.03 *$ & & $-3.77 *$ & \\
\hline & F3 & 1.18 & & -0.81 & & 0.30 & \\
\hline & F4 & -3.08 & & 2.04 & & 0.30 & \\
\hline
\end{tabular}

F1: Dissolution medium, F2: Apparatus, F3: Time, F4: Stirring speed. * Statically significant values

(Table 2). Taking into account the analytical responses as drug release percent (DR\%), the effects of the four factors and their respective errors were calculated and are shown in Table 3 . When the effects of factorial design exceed the estimated error for each product in a level of $95 \%$ of confidence interval, this effect becomes statistically significant. ${ }^{31}$ Furthermore, variables with positive effects indicate that an increase of their level provides a significant increase in the DR \% and negative effects mean that higher percentage of drug release is obtained with decrease in the levels of the variables.

Considering HPLC method, only F4 (stirring speed) was statistically significant with a negative effect $(-2.78)$ for product A. For product B, only F4 is significant too, however the effect was positive (2.77). One possible explanation for this paradoxical effect is the difference of the excipients contained in each product A and B. In the case of product $\mathrm{A}$, the increase of the agitation speed could have favored the interaction of its excipients with the active principle, ${ }^{36}$ resulting in a smaller analytical responses, which was not observed with product $\mathrm{B}$. However, when the experiments were carried out with stirring speed of $50 \mathrm{rpm}$ the drug release percent (DR\%) was higher than $80 \%$ in all products (Table 2). This effect was observed due to the high aqueous solubility of losartan potassium. ${ }^{6}$ Therefore, this factor was fixed at $50 \mathrm{rpm}$ because this stirring speed is enough to assure an effective drug release of products. Moreover, a maximum discriminatory power should be obtained with lower stirring rate. ${ }^{36}$

Regarding spectrophotometric detection, F2 (apparatus) was statistically significant. The negative effect for both products B (-3.03) and $\mathrm{C}(-3.77)$ indicates that the basket is an adequate stirring apparatus. This result is in accordance with USP 30 that recommends basket apparatus for dissolution test of capsules. ${ }^{3}$

The factor F1 (dissolution mediums) is not significant for all products, considering both detection methods. Therefore, both mediums (phosphate buffer pH 6.8 and water) could be used in the subsequent analysis. However, the use of water as a dissolution medium is discouraged because test conditions such as $\mathrm{pH}$ and surface tension can vary depending on the water source and may change during the dissolution test itself. ${ }^{1}$ For this reason, the phosphate buffer $\mathrm{pH} 6.8$ was chosen as dissolution medium. The 0.1 and $0.01 \mathrm{~mol} \mathrm{~L}^{-1} \mathrm{HCl}$ was not used for establishment of dissolution medium because the drug was not dissolved in both solutions, and a precipitate was observed during the establishment of sink conditions.

The time of $30 \mathrm{~min}$ is not statistically different from $60 \mathrm{~min}$. Consequently, the time of 30 min was chosen considering the importance 
of analytical frequency in pharmaceutical quality control laboratories.

Therefore, the established conditions after $2^{4}$ full factorial design were: $900 \mathrm{~mL}$ of phosphate buffer, $\mathrm{pH} 6.8$ at $37{ }^{\circ} \mathrm{C}$ as dissolution medium, basket as apparatus at the stirring speed of $50 \mathrm{rpm}$ and collection in $30 \mathrm{~min}$.

\section{Method validation}

\section{Selectivity}

Placebo formulations for products $\mathrm{A}, \mathrm{B}$ and $\mathrm{C}$ did not present $\mathrm{ab}-$ sorbance at $205 \mathrm{~nm}$. However, A, B and C capsule shells presented a significantly UV absorbance (Figure 2). For this reason, in this method one capsule shell of each product was analyzed in a separate vessel under the same optimized conditions and the absorbance value was subtracted from the sample solution absorbance to eliminate this interference.

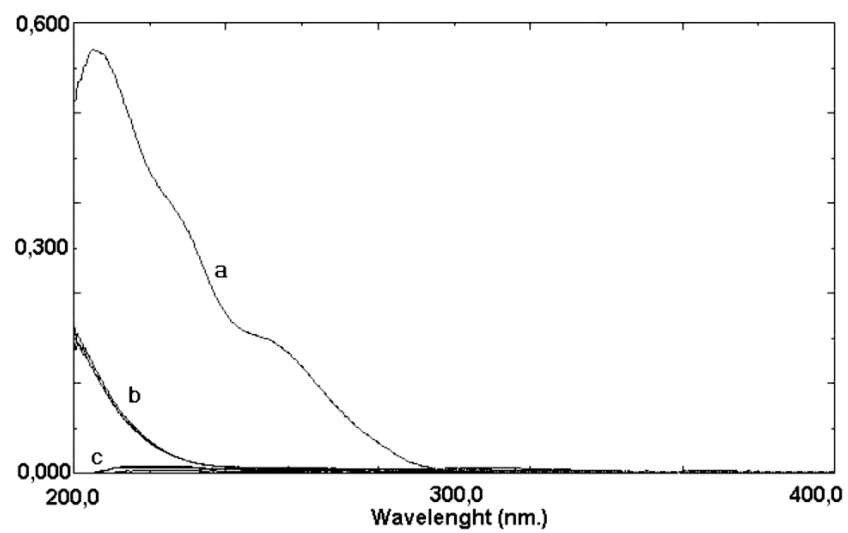

Figure 2. UV spectrum of losartan potassium (a), empty capsules $A, B$ and $C(b)$ and placebo samples $A, B$ and $C(c)$, after dissolution test using basket at $150 \mathrm{rpm}$ for $60 \mathrm{~min}$. The aliquots were diluted 10-fold

In the HPLC method no additional chromatographic peaks from the placebo formulations and empty capsules were observed with the same retention time for losartan potassium, which demonstrates the selectivity of this method (Figure 3 ).

\section{Linearity}

The calibration equations obtained from HPLC and spectrophotometry were: peak area $=18994\left[\operatorname{losartan} \operatorname{potassium}\left(\mathrm{mg} \mathrm{L}^{-1}\right)\right]+19753$ and $\mathrm{abs}=0.0891\left[\right.$ losartan potassium $\left.\left(\mathrm{mg} \mathrm{L}^{-1}\right)\right]-0.0011$, respectively

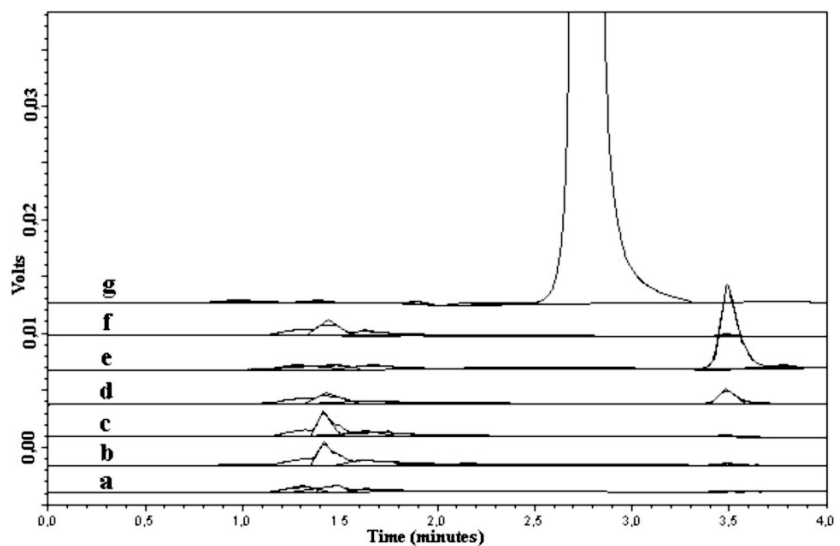

Figure 3. Chromatogram of placebo sample of product $A(a)$, placebo sample of product $B(b)$, placebo sample of product $C(c)$, empty capsule $A(d)$, empty capsule $B(e)$, empty capsule $C(f)$ and a work standard solution of losartan potassium $55.6 \mathrm{mg} \mathrm{L}^{-1}$ in phosphate buffer $\mathrm{pH} 6.8(\mathrm{~g})$
The least square regression showed excellent correlation coefficients: $\mathrm{r}=1.0000$ and 0.9999 for HPLC and spectrophotometric methods, respectively. The relative standard deviation of each point $(n=5)$ was smaller than $2 \%$. The results meeting the acceptance criteria. ${ }^{33}$

Repeatability (intra-assay) and intermediate precision (interassay) of the analytical methods

The results of the repeatability (intra-assay) and intermediate precision (inter-assay) of the methods are shown in Table 4. The relative standard deviations did not exceed $2.0 \%$ for both methods, demonstrating suitable precision. ${ }^{37}$

Table 4. Results of precision of the HPLC and spectrophotometric analytical methods for losartan potassium in capsules

\begin{tabular}{lccc}
\hline Method & Level & $\begin{array}{c}\text { Concentration } \\
\left(\mathrm{mg} \mathrm{L}^{-1}\right)\end{array}$ & R.S.D. $(\%)$ \\
\hline HPLC & $\begin{array}{c}\text { Repeatability } \\
\text { Intermediate } \\
\text { precision }\end{array}$ & 55.6 & $0.57(\mathrm{n}=6)$ \\
Spectrophotometry & $\begin{array}{c}\text { Repeatability } \\
\text { Intermediate } \\
\text { precision }\end{array}$ & 5.56 & $0.53(\mathrm{n}=12)$ \\
& 5.56 & $1.07(\mathrm{n}=12)$ \\
\hline
\end{tabular}

Repeatability (intra-assay) and intermediate precision (interassay) of the dissolution procedure

The results of the repeatability (intra-assay) and intermediate precision (inter-assay) of the dissolution procedure using HPLC and spectrophotometry are shown in Table 5. The relative standard deviations did not exceed $5.0 \%$, demonstrating suitable precision for the dissolution test. ${ }^{37}$

Table 5. Results of the dissolution procedure precision using HPLC and spectrophotometry for losartan potassium in capsules

\begin{tabular}{|c|c|c|c|c|}
\hline Method & Level & Product & $\begin{array}{l}\text { Concentration } \\
\qquad\left(\mathrm{mg} \mathrm{L}^{-1}\right)\end{array}$ & $\begin{array}{c}\text { R.S.D. } \\
(\%)\end{array}$ \\
\hline \multirow[t]{6}{*}{ HPLC } & \multirow[t]{3}{*}{ Repeatability } & $\mathrm{A}$ & 55.6 & $3.43(n=6)$ \\
\hline & & B & 55.6 & $4.08(n=6)$ \\
\hline & & $\mathrm{C}$ & 55.6 & $3.45(n=6)$ \\
\hline & \multirow{3}{*}{$\begin{array}{l}\text { Intermediate } \\
\text { precision }\end{array}$} & A & 55.6 & $3.93(n=12)$ \\
\hline & & B & 55.6 & $3.42(n=12)$ \\
\hline & & $\mathrm{C}$ & 55.6 & $2.97(\mathrm{n}=12)$ \\
\hline \multirow{6}{*}{$\begin{array}{l}\text { Spectropho- } \\
\text { tometry }\end{array}$} & \multirow[t]{3}{*}{ Repeatability } & A & 5.56 & $3.27(n=6)$ \\
\hline & & B & 5.56 & $3.43(n=6)$ \\
\hline & & $\mathrm{C}$ & 5.56 & $2.86(n=6)$ \\
\hline & \multirow{3}{*}{$\begin{array}{c}\text { Intermediate } \\
\text { precision }\end{array}$} & A & 5.56 & $3.31(n=12)$ \\
\hline & & B & 5.56 & $2.71(n=12)$ \\
\hline & & $\mathrm{C}$ & 5.56 & $2.79(\mathrm{n}=12)$ \\
\hline
\end{tabular}

Accuracy of the analytical methods

The values of analytical methods accuracy for losartan potassium in all drug products are summarized in Table 6 . The average values are between $98.0-102.0 \%$ for both methods, showing good recovery. ${ }^{37}$

\section{Accuracy of the dissolution procedure}

The values of dissolution procedure accuracy for losartan potassium in all drug products shown in Table 7 are between $95.0-105.0 \%$, showing good recovery according to literature. ${ }^{37}$ 
Table 6. Results of accuracy of the HPLC and spectrophotometric analytical methods for losartan potassium in capsules

\begin{tabular}{|c|c|c|c|c|c|}
\hline \multirow[t]{2}{*}{ Method } & \multirow[t]{2}{*}{ Product } & \multicolumn{2}{|c|}{$\begin{array}{l}\text { Final concentration } \\
\qquad\left(\mathrm{mg} \mathrm{L}^{-1}\right)\end{array}$} & \multirow{2}{*}{$\begin{array}{l}\text { R.S.D. } \\
(\%) \mathrm{n}=3\end{array}$} & \multirow{2}{*}{$\begin{array}{c}\text { Mean } \\
\text { recovery } \\
(\%)\end{array}$} \\
\hline & & Added & Found & & \\
\hline \multirow[t]{9}{*}{ HPLC } & A & 44.48 & 44.50 & 0.40 & \multirow{3}{*}{99.50} \\
\hline & B & 55.60 & 56.19 & 0.97 & \\
\hline & $\mathrm{C}$ & 66.72 & 65.00 & 1.17 & \\
\hline & A & 44.48 & 44.50 & 1.46 & \multirow{3}{*}{98.20} \\
\hline & B & 55.60 & 55.10 & 0.51 & \\
\hline & $\mathrm{C}$ & 66.72 & 63.77 & 2.49 & \\
\hline & A & 44.48 & 45.38 & 1.48 & \multirow{3}{*}{101.40} \\
\hline & B & 55.60 & 56.75 & 1.56 & \\
\hline & $\mathrm{C}$ & 66.72 & 66.81 & 0.98 & \\
\hline \multirow{9}{*}{$\begin{array}{l}\text { Spectropho- } \\
\text { tometry }\end{array}$} & A & 4.45 & 4.36 & 0.75 & \multirow{3}{*}{99.3} \\
\hline & B & 5.56 & 5.55 & 0.51 & \\
\hline & $\mathrm{C}$ & 6.67 & 6.66 & 1.33 & \\
\hline & A & 4.45 & 4.31 & 0.24 & \multirow{3}{*}{98.5} \\
\hline & B & 5.56 & 5.57 & 0.87 & \\
\hline & $\mathrm{C}$ & 6.67 & 6.58 & 0.09 & \\
\hline & A & 4.45 & 4.46 & 1.00 & \multirow{3}{*}{100.1} \\
\hline & B & 5.56 & 5.57 & 0.11 & \\
\hline & $\mathrm{C}$ & 6.67 & 6.66 & 0.25 & \\
\hline
\end{tabular}

\section{Detection limit and quantitation limit}

The detection limits of the HPLC and spectrophotometric methods were found to be 0.013 and $0.08 \mathrm{mg} \mathrm{L}^{-1}$, respectively. The quantitation limits of the HPLC and spectrophotometry were found to be 0.22 and $0.26 \mathrm{mg} \mathrm{L}^{-1}$, respectively. The precision experiments at the QL level yielded R.S.D. of 2.0 and $1.9 \%(n=3)$ for HPLC and spectrophotometric methods, respectively.

\section{Disintegration}

All formulations met the compendial requirements for capsules ${ }^{3}$ (disintegration time $<20$ minutes). Disintegration times were 5 min and $11 \mathrm{~s} ; 4$ min and $52 \mathrm{~s}$ and $5 \mathrm{~min}$ and $35 \mathrm{~s}$ for products A, B and $\mathrm{C}$, respectively.

\section{Dissolution profiles}

The validated methods were used in the analysis of three losartan potassium capsules supplied from three different manufacturers. Dissolution profiles of each product using HPLC and spectrophotometric
Table 7. Results of the dissolution procedure accuracy using HPLC and spectrophotometry for losartan potassium in capsules

\begin{tabular}{|c|c|c|c|c|c|}
\hline \multirow[t]{2}{*}{ Method } & \multirow[t]{2}{*}{ Product } & \multicolumn{2}{|c|}{$\begin{array}{l}\text { Final concentration (mg } \\
\left.\qquad \mathrm{L}^{-1}\right)\end{array}$} & \multirow{2}{*}{$\begin{array}{l}\text { R.S.D. } \\
\text { (\%) } \mathrm{n}=3\end{array}$} & \multirow{2}{*}{$\begin{array}{c}\text { Mean } \\
\text { recovery } \\
(\%)\end{array}$} \\
\hline & & Added & Found & & \\
\hline \multirow[t]{9}{*}{ HPLC } & A & 44.44 & 43.09 & 0.40 & \multirow{3}{*}{97.40} \\
\hline & \multirow{2}{*}{$\mathrm{C}$} & 55.56 & 55.54 & 0.97 & \\
\hline & & 66.67 & 63.53 & 1.17 & \\
\hline & A & 44.44 & 45.71 & 1.46 & \multirow{3}{*}{99.10} \\
\hline & B & 55.56 & 54.12 & 0.51 & \\
\hline & $C$ & 66.67 & 64.67 & 2.49 & \\
\hline & A & 44.44 & 42.18 & 1.48 & \\
\hline & B & 55.56 & 52.09 & 1.56 & \\
\hline & $C$ & 66.67 & 64.75 & 0.98 & 90.50 \\
\hline \multirow{9}{*}{$\begin{array}{l}\text { Spectropho- } \\
\text { tometry }\end{array}$} & A & 4.44 & 4.47 & 0.98 & \multirow{3}{*}{100.9} \\
\hline & B & 5.56 & 5.58 & 0.68 & \\
\hline & $\mathrm{C}$ & 6.67 & 6.78 & 0.54 & \\
\hline & A & 4.44 & 4.71 & 1.84 & \multirow{3}{*}{103.8} \\
\hline & B & 5.56 & 5.67 & 1.48 & \\
\hline & $\mathrm{C}$ & 6.67 & 6.90 & 0.27 & \\
\hline & A & 4.44 & 4.40 & 4.49 & \multirow{3}{*}{99.6} \\
\hline & B & 5.56 & 5.64 & 1.65 & \\
\hline & $\mathrm{C}$ & 6.67 & 6.55 & 1.24 & \\
\hline
\end{tabular}

detection are presented in Figures 4 and 5, respectively. The results are expressed as losartan potassium concentration dissolved versus time (min). All three products tested showed $>95 \%$ dissolution in $30 \mathrm{~min}$. These results are in accordance to FDA, ${ }^{1}$ which recommended that for highly soluble and rapidly dissolving drug products (BCS classes 1 and 3), a single-point dissolution test specification of $85 \%$ in $60 \mathrm{~min}$ or less is sufficient as a routine quality control test for batch-to-batch uniformity. Therefore, $30 \mathrm{~min}$ can be considered satisfactory to evaluate the release-time of losartan potassium in capsules, in agreement with the results of factorial design. So, the acceptance criterion of $85 \%$ in 30 min was established.

\section{Comparison of methods}

Table 8 presents the data obtained by ANOVA, where the analytical methods were statistically compared. The results obtained show that there are no significant differences between HPLC and spectrophotometric analytical methods as well as interactions between methods and products.

Table 8. ANOVA data for comparative analysis of HPLC and spectrophotometric quantitation methods

\begin{tabular}{lccccc}
\hline Factors & D. F. & S. S. & M. S. & F & P \\
\hline Method & 1 & 110.811037 & 110.811037 & 0.064 & 3.030 \\
Product & 2 & 10470.681078 & 5235.340539 & 0.8003 & 0.062 \\
M x P & 2 & 212.578078 & 106.289039 & & \\
Error & 210 & 362818.692003 & 1727.708057 & & \\
Total & 215 & 373612.762196 & & \\
\hline
\end{tabular}

M x P: interaction between method and product; D. F.: degrees of freedom; S. S.: sum of squares; M. S.: mean square; F: F-ratio; P: P value (values above 0.05 indicates that there are no significant differences between treatments) 


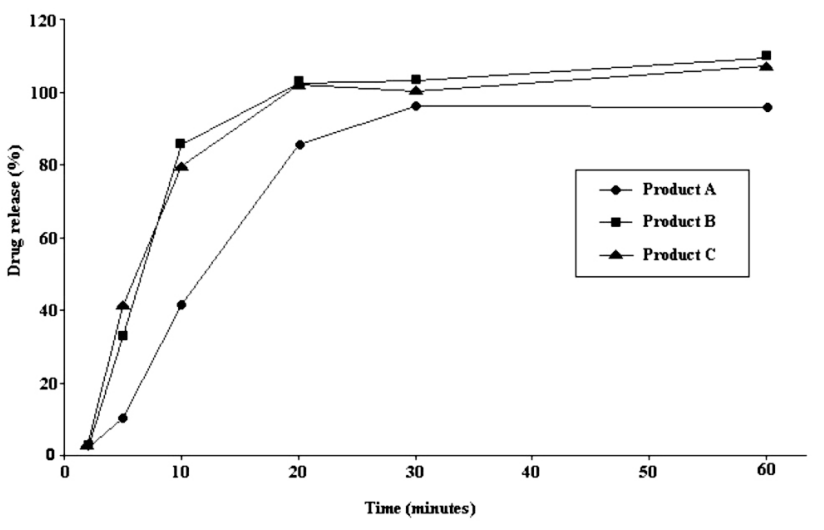

Figure 4. Dissolution profile of $50 \mathrm{mg}$ capsules losartan potassium products codified as A, B and C under optimal dissolution conditions using HPLC method

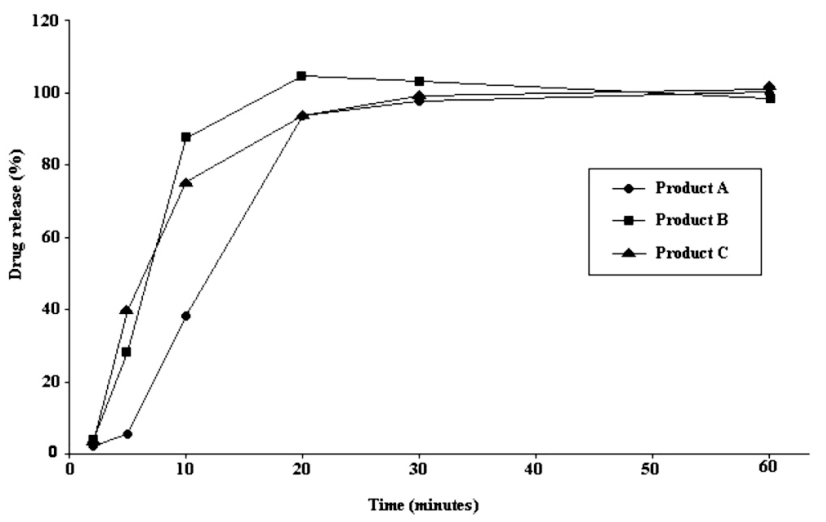

Figure 5. Dissolution profile of $50 \mathrm{mg}$ capsules losartan potassium products codified as A, B and C under optimal dissolution conditions using spectrophotometric method

\section{CONCLUSION}

In this work, a dissolution test for losartan potassium in capsules was developed. Screening study using a $2^{4}$ full factorial design was conducted to select the dissolution medium, rotation speed, dissolution apparatus and stirring speed. This strategy produces a reduction in the total number of simulations necessary to obtain a satisfactory result. The validation results demonstrated that the in vitro dissolution test using both HPLC and spectrophotometric analytical methods was accurate, precise, linear and selective. This study illustrates the importance of an official method for dissolution test, since there is no official monograph for losartan potassium in capsules.

\section{ACKNOWLEDGEMENTS}

The authors are grateful to Center of Pharmaceutical Equivalence of the Nucleus Control of Quality and the UNIFAL-MG for the financial support. The author C. R. T. Tarley is grateful to the CNPq for fellowship.

\section{REFERENCES}

1. United States Food and Drug Administration, Center for Drug Evaluation and Research (CDER); Dissolution Testing of Immediate Release Solid Oral Dosage Forms. Guidance for Industry, Rockville, 1997.

2. Dressman, J. B.; Amidon, G. L.; Reppas, C.; Shah, C. V. P.; Pharm. Res. 1998, $15,11$.
3. The United States Pharmacopeia, $31^{\text {th }}$ ed., United States Pharmacopoeial Convention: Rockville, 2008.

4. Schoenberger, J. A.; J. Hypertens. 1995, 13, S43.

5. Hertzog, D. L.; McCafferty, J. F.; Fang, X.; Tyrrell, R. J.; Reed, R. A.; J. Pharm. Biomed. Anal. 2002, 30, 747.

6. Williams, R. C.; Alasandro, M. S.; Fasone, V. L.; Boucher, R. J.; Edwards, J. F.; J. Pharm. Biomed. Anal. 1996, 14, 1539.

7. Soldner, A.; Spahn-Langguth, H.; Mutschler, E.; Br. J. Pharmacol. 2000, 129, 1235.

8. Lo, M. W.; Goldberg, M. R.; Mccrea, M. R.; Lu, H.; Furtek, C. I.; Bjornsson, T. D.; Clin. Pharmacol. Ther. 1995, 58, 641.

9. Furtek, C. I.; Lo, M. W.; J. Chromatogr., A 1992, 573, 295.

10. Lee, H.; Shim, H. O.; Lee, H. S.; Chromatographia 1996, $42,39$.

11. Yeung, P. K.; Jamieson, A.; Smith, G. J.; Fice, D.; Pollak, P. T.; Int. J. Pharm. 2000, 204, 17.

12. Kristoffersen, L.; Øiestad, E. L.; Opdal, M. S.; Krogh, M.; Lundanes, E.; Christophersen, A. S.; J. Chromatogr., B 2007, 850, 147.

13. Soldner, A.; Benet, L.; Mutschler, Z. E.; Christians, U.; Br. J. Pharmacol. 2000, 129, 1235.

14. Erk, N.; J. Pharm. Biomed. Anal. 2001, 24, 603.

15. Ansari, M.; Kazemipour, M.; Khosravi, F.; Baradaran, M.; Chem. Pharm. Bull. 2004, 52, 1166.

16. Zhao, Z.; Wang, Q.; Tsai, E.; Qin, X.; Ip, D.; J. Pharm. Biomed. Anal. 1999, 20, 129.

17. Carlucci, G.; Palumbo, G.; Mazzeo, P.; Quaglia, M. G.; J. Pharm. Biomed. Anal. 2000, 23, 185.

18. Maio, V. M. P.; Dias, C. L.; Bergold, A. M.; Lat. Am. J. Pharm. 2005, 24,250 .

19. Lusina, M.; Cindri'c, T.; Tomai'c, J.; Peko, M.; Pozai'c, L.; Musulin, N.; Int. J. Pharm. 2005, 291, 127.

20. Obando, M. A.; Estela, J. M.; Cerda, V.; Anal. Bioanal. Chem. 2008, $391,2349$.

21. Seburg, R.; Ballard, J. M.; Hwang, T.; Sullivan, C. M.; J. Pharm. Biomed. Anal. 2006, 42, 411.

22. Sreekanth, N.; Shivshanker, K.; Shanmuga Pandian, P.; Roosewelt, C.; Srinivasa Rao, G.; Gunasekaran, V.; Asian J. Chem. 2007, 19, 2850.

23. McCarthy, K. E.; Wang, Q.; Tsai, E. W.; Gilbert, R. E.; Ip, D. P.; Brooks, M. A.; J. Pharm. Biomed. Anal. 1998, 17, 671.

24. Sathe, S. R.; Bari, S. B.; Acta Chromatogr. 2007, 19, 270.

25. Quaglia, M. G.; Donati, E.; Carlucci, G.; Mazzeo, P.; Fanali, S.; J. Pharm. Biomed. Anal. 2002, 29, 981.

26. Lastra, O. C.; Lemus, I. G.; Sánchez, H. J.; Pérez, R. F.; J. Pharm. Biomed. Anal. 2003, 33, 175.

27. Maggio, R. M.; Castellano, P. M.; Kaufman, T. S.; Anal. Bioanal. Chem. 2008, 391, 2949.

28. Prabhakar, A. H.; Giridhar, R.; J. Pharm. Biomed. Anal. 2002, 27, 861.

29. Neves, R.; Arzneim. Forsch. 2008, 58, 369.

30. Choi, Y.; J. Liq. Chromatogr. Relat. Technol. 2008, 31, 2643.

31. Montgomery, D. C. Em Design and Analysis of Experiments; Montgomery, D. C., ed.; Wiley: New York, 2000, p. 177-185.

32. Breier, A. R.; Paim, C. S.; Steppe, M.; Schapoval, E. E. S.; J. Pharm. Pharm. Sci. 2005, 8, 289.

33. International Conference on Harmonisation (ICH); Validation of Analytical Procedures: Methodology, Q2B, Consensus Guideline, 6 November 1996.

34. Azevedo, R. C. P.; Ribeiro, G. P.; Araújo, M. B.; Rev. Bras. Ciênc. Farm. 2008, 44, 261.

35. Bonfilio, R.; Tarley, C. R. T.; Pereira, G. R.; Salgado, H. R. N.; Araújo, M. B.; Talanta 2009, 80, 236.

36. Shah, V. P.; Gurbarg, M.; Noory, A.; Dighe, J. P.; Skelly, J. P.; J. Pharm. Sci. 1992, 81, 500.

37. Marques, M.R.C.; Brown, W.; Rev. Anal. 2002, 1, 48. 